\title{
Prognostic factors in head and neck cancer: a 10-year retrospective analysis in a single-institution in Italy
}

\author{
Fattori prognostici del tumore testa-collo: un'analisi retrospettiva monocentrica \\ di 10 anni \\ G. CADONI ${ }^{1}$, L. GIRALDI ${ }^{2}$, L. PETRELLI ${ }^{1}$, M. PANDOLFINI ${ }^{1}$, M. GIULIANI ${ }^{1}$, G. PALUDETTI ${ }^{1}$, R. PASTORINO ${ }^{2}$, \\ E. LEONCINI ${ }^{2}$, D. ARZANI', G. ALMADORI ${ }^{1}$, S. BOCCIA ${ }^{3}$ \\ ${ }^{1}$ Institute of Otorhinolaryngology, Università Cattolica del Sacro Cuore, Fondazione Policlinico Universitario \\ "Agostino Gemelli", Rome, Italy; ${ }^{2}$ Section of Hygiene, Institute of Public Health, Università Cattolica del Sacro \\ Cuore, Rome, Italy; ${ }^{3}$ Section of Hygiene, Institute of Public Health, Università Cattolica del Sacro Cuore, \\ Fondazione Policlinico Universitario "Agostino Gemelli", Rome, Italy
}

\begin{abstract}
SUMMARY
This study was undertaken to evaluate the association between demographics, lifestyle habits, and clinical data and overall survival (OS), recurrence and second primary cancer (SPC) in patients with first primary head and neck cancer (HNC). We retrospectively reviewed data from 482 patients treated at the "Agostino Gemelli" Teaching Hospital, Rome, between 2002-2012 for primary HNC. Individual parameters were evaluated for association with specific outcomes such as OS, cancer recurrence and second primary cancer (SPC) appearance using hazard ratios (HR) and 95\% confidence intervals (CIs). Five-year OS was 60.6\% for all HNC cases, $49.0 \%$ for oral cavity, 54.8\% for oropharynx, 50.0\% for hypopharynx and $63.4 \%$ for larynx. Predictors of OS were older age $(\mathrm{HR}=1.04 ; 95 \%$ CI: 1.02-1.05) and advanced tumour stage $(\mathrm{HR}=2.00$; 95\% CI: 1.41-2.84). The risk of recurrence was associated with drinking 8-14 drinks per week (HR =1.73; 95\% CI: 1.00-2.97). The risk of developing SPC increased with advanced tumour stage $(\mathrm{HR}=2.75 ; 95 \% \mathrm{CI}$ : 1.39-5.44) and with smoking for more than 40 years $(\mathrm{HR}=3.68 ; 95 \%$ CI: 1.10-12.30). OS differed among HNC sites. Increasing age was an unfavourable predictor of HNC OS. Tumour stage was a prognostic factor both for OS and for risk of developing SPC. Alcohol and tobacco consumption were prognostic factors for recurrence and SPC, respectively.
\end{abstract}

KEY WORDS: Head and neck cancer • Prognostic factors • Epidemiology

\begin{abstract}
RIASSUNTO
$\grave{E}$ stata condotta un'analisi retrospettiva su 482 pazienti con diagnosi di tumore testa-collo arruolati presso l' ospedale "Agostino Gemelli" di Roma. L'associazione tra fattori demografici, clinici e comportamentali con la overall survival (OS), il rischio di ricorrenza ed il rischio di un secondo tumore primitivo è stata stimata usando gli Hazard Ratio (HR) e gli intervalli di confidenza al 95\% (CIs). La OS considerando tutte le sedi tumorali è stata del 60\%, mentre considerando le singole sedi tumorali è risultata del $49.0 \%$ per il cavo orale, $54.8 \%$ per l'orofaringe, $50.0 \%$ per l'ipofaringe e $63.4 \%$ per la laringe. Un'età avanzata alla diagnosi (HR = 1.04; 95\% CI: 1.02-1.05) ed un avanzato stadio del tumore (HR $=2.00 ; 95 \%$ CI: $1.41-2.84)$ sono risultati fattori significativamente associati con la OS. Il rischio di ricorrenza è risultato associato con il consumo di alcolici $(H R=1.73 ; 95 \%$ CI: 1.00-2.97). Il rischio di sviluppare un secondo tumore primitivo è risutlato associato con uno stadio avanzato del tumore primario (HR $=2.75$; $95 \%$ CI: 1.39-5.44) e con l'aver fumato per più di 40 anni $(H R=3.68 ; 95 \%$ CI: 1.10-12.30). In conclusione abbiamo notato che la OS differisce tra le sedi tumorali del tumore testa-collo. Lo stadio tumorale è risultato essere associato sia con la OS che con il rischo di sviluppare un secondo tumore primitivo. Il consumo di alcol e di tabacco sono risultati essere fattori prognostici, rispettivamente, per la ricorrenza e per l'insorgenza di un secondo tumore primitivo.
\end{abstract}

PAROLE CHIAVE: Cancro della testa e del collo $\bullet$ Fattori prognostici $\bullet$ Epidemiologia

Acta Otorhinolaryngol Ital 2017;37:458-466

\section{Introduction}

Squamous cell carcinoma of the head and neck (HNC) is the sixth common cancer worldwide affecting 600,000 new cases diagnosed each year ${ }^{1}$. In 2009 in Italy there were an estimated 1008 new HNC cases (790 males and 218 females) with a 5-year survival rate of 55\% (2000-2004) ${ }^{2}$.
Various genetic and environmental factors are related to $\mathrm{HNC}^{3}$. The incidence of HNC has a large geographical variability related to different prevalence of lifestyle risk factors, such as alcohol drinking, tobacco smoking and dietary factors ${ }^{4-12}$. Other known risk factors are human papillomavirus (HPV) ${ }^{13}$ and Epstein-Barr virus (EBV) 
infections ${ }^{14}$. Men have a higher risk having a HNC than women ${ }^{1}$.

The most frequent tumour sites of HNC are the larynx, oral cavity and pharynx. Head and neck cancers also include salivary gland tumours as well as nasopharyngeal cancer and paranasal and nasal sinus cancer. These tumours are less frequent and will not be discussed in this report.

The management of HNC is often a clinical challenge, since in more than $60 \%$ of patients the disease is locally advanced at diagnosis: a combined modality therapy with surgery, radiotherapy and chemotherapy is generally recommended ${ }^{15}$. When the disease is deemed unresectable or an organ-preservation goal is pursued, the current standard treatment is represented by the combination of radiation and chemotherapy ${ }^{16}$.

In head and neck oncology, the lack of well-defined prognostic and predictive factors limits the possibility to tailor the best therapeutic approach on an individual basis.

In this study, we retrospectively evaluated the association of individual parameters with specific outcomes in terms of disease control in a cohort of 482 patients treated at our Italian centre to identify predictive and prognostic factors that could help clinicians in deciding the most appropriate treatment.

\section{Materials and methods}

Subjects with histologically confirmed primary squamous cell carcinoma of the head and neck cancer were consecutively recruited at the Gemelli Hospital, from 2002 to 2012. The study was approved by the Ethics Committee of the University. Details of the tumour classification used have been described previously ${ }^{17}$.

\section{Data collection}

Patients were interviewed face-to-face by trained interviewers or physicians on demographic, alcohol and tobacco consumption, and other relevant lifestyle factors. Interviews were conducted from 15 to 5 days prior to treatment. Questions assessed information at one year before diagnosis. Participant were also followed from the date of diagnosis to the date of death, or loss to follow up, whichever occurred first. Death certificate data were also used for mortality, and the cause of death was coded according to the International Classification of Diseases, Ninth Revision ${ }^{18}$. Cancer recurrence and SPC were collected from medical records and cancer registries. Data on tumour pathology and treatment were obtained from pathology records.

\section{Diagnostic and therapeutic guidelines}

Pre-treatment work up included: complete head and neck exam, biopsy, chest imaging, CT with contrast and/or MRI with contrast of primary and neck; FDG-PET /CT for stage III-IV disease, nutrition, speech and swallowing evaluation, multidisciplinary consultation. Tumour HPV testing was performed in oropharynx primary in the last years.

The therapeutic guidelines used were as follows: oral cavity, early stage T1-T2 N0 surgery; advanced stage (T3N, T1-T3 -N1-N3, T4a any N) surgery or multidisciplinary approach.

Oropharynx: early stage (T1-T2, N0-1) definitive radiotherapy (RT) or surgery; advanced stage (T3, T4a, N0N1) concurrent systemic therapy/RT or surgery or induction chemotherapy followed by radiotherapy or systemic therapy/RT.

Hypopharynx: early stage (T1-selected T2 N0) definitive RT or surgery; advanced stage (T2-3, any N and t1 N+; $\mathrm{T} 4 \mathrm{a}$ any $\mathrm{N}$ ) induction chemotherapy or surgery or concurrent systemic therapy/RT.

Larynx: early stage (T1-T2 or selected T3) surgery or RT; $\mathrm{T} 3$ requiring total laryngectomy any $\mathrm{N}$ concurrent systemic therapy/RT or RT if patient not candidate for systemic therapy/RT or surgery or induction chemotherapy; $\mathrm{T} 4$ any $\mathrm{N}$ surgery.

\section{Outcome definitions}

The primary endpoint was overall survival (OS) measured as the time from the date of initial diagnosis of index primary tumours to the date of death from any cause. All observations were censored at loss to follow-up and at the end of the study period. Recurrence was defined as the local, regional or distant return of cancer after that the patient was defined as disease free. By definition, a second primary tumour of the same histologic type as the first had to be separated from it by more than $2 \mathrm{~cm}$ of normal epithelium or had to occur at least 3 years after diagnosis of the first primary tumour. Any new tumour of a different histologic type was characterised as a second primary tumour without the requirement of separation of more than $2 \mathrm{~cm}^{19}$.

\section{Statistical analysis}

We used the Kaplan-Meier method to calculate the cumulative proportion surviving and to plot survival curves. We used multivariable Cox's proportional hazards model to determine independent predictors of OS, recurrence and SPC. We formally tested the Cox proportional hazards assumption for each covariate using Schoenfeld residuals ${ }^{20}$. Hazard ratios (HR) for all-cause mortality were adjusted for age, tumour stage and lymph nodes.

Models to predict SPC were adjusted for age, tumour stage, years of smoking and presence of lymph nodes. Models to predict recurrence were adjusted for age, treatment and lymph nodes. With respect to smoking, patients were classified as never, former or current smokers. $\mathrm{Cu}$ mulative tobacco consumption was calculated as intensity of smoking (never smokers, $\leq 20$ cigarettes/day, $>20$ ciga- 
rettes/day), and smoking duration in years (never smokers, $\leq 20,21-40,>40$ ). With respect to alcohol, subjects were classified as never drinkers, former and current, and according to alcohol consumption (none or $<1$ drink equivalent/week, 1-7 drinks/week, 8-14 drinks/ week, 15-21 drinks/week, 22-28 > 29 drinks/week). The standard definition for one drink equivalent was $14 \mathrm{~g}$ ethanol, which approximately corresponds to $150 \mathrm{~mL}$ wine, $330 \mathrm{~mL}$ beer, and $36 \mathrm{~mL}$ spirits ${ }^{21}$. Analysis were performed for overall HNC. Statistical analyses were performed using Stata software, version 13 (StataCorp. 2013. Stata Statistical Software: Release 13. College Station, TX: StataCorp LP).

\section{Results}

A total of 482 subjects were included in the study. Characteristics of the patients are reported in Table I. Disease location was the oral cavity in $83(17.2 \%)$ patients, oropharynx in $84(17.4 \%)$, hypopharynx in $20(4.2 \%)$, larynx in $290(60.2 \%)$. For 5 patients $(1.0 \%)$ the disease location was oral cavity or pharynx not otherwise specified. There was a high predominance of male cases $(79.1 \%)$ and median age at diagnosis was 64 (interquartile range (IQR): 57-70) years old overall. Most patients presented an advanced tumour at the time of diagnosis (Stage IIIIV $=54.2 \%)$. Lymph nodes are not involved frequently

Table I. Characteristics of head and neck cancer cases by tumour site.

\begin{tabular}{|c|c|c|c|c|c|c|c|c|}
\hline Tumor site & $\begin{array}{c}\text { Subjects } \\
\mathrm{n}(\%)\end{array}$ & $\begin{array}{l}\text { Gender } \\
\text { (\% male) }\end{array}$ & $\begin{array}{c}\text { Age } \\
\text { (median, IQR*) }\end{array}$ & & $\begin{array}{l}\text { ge } \\
\%)\end{array}$ & Lymph node $\mathrm{n}(\%)$ & & $\begin{array}{l}\text { Tumour size } \\
\text { n (\%) }\end{array}$ \\
\hline \multirow[t]{5}{*}{ Oral cavity } & 83 (17.2) & $59.0 \%$ & $64(51-71)$ & $1-2$ & $29(34.9)$ & $0(0)$ & 1 & $11(13.9)$ \\
\hline & & & & & & & 2 & $29(36.7)$ \\
\hline & & & & $3-4$ & $54(65.1)$ & $26(51.0)$ & 3 & $10(12.7)$ \\
\hline & & & & & & & 4 & $29(36.7)$ \\
\hline & & & & Missing & $0(0)$ & $4(4.8)$ & & $4(4.8)$ \\
\hline \multirow[t]{5}{*}{ Oropharynx } & $84(17.4)$ & $75.3 \%$ & $61(52-68.5)$ & $1-2$ & 31 (36.9) & $0(0)$ & 1 & $13(15.5)$ \\
\hline & & & & & & & 2 & $32(38.1)$ \\
\hline & & & & $3-4$ & $53(63.1)$ & $41(77.4)$ & 3 & $7(8.3)$ \\
\hline & & & & & & & 4 & $32(38.1)$ \\
\hline & & & & Missing & $0(0)$ & $0(0)$ & & $0(0)$ \\
\hline \multirow[t]{5}{*}{ Hypopharynx } & $20(4.2)$ & $65.0 \%$ & $61(58-66)$ & $1-2$ & $1(5)$ & $0(0)$ & 1 & $1(5.0)$ \\
\hline & & & & & & & 2 & $3(15.0)$ \\
\hline & & & & $3-4$ & $19(95)$ & $14(73.7)$ & 3 & $3(15.0)$ \\
\hline & & & & & & & 4 & $13(65.0)$ \\
\hline & & & & Missing & $0(0)$ & $0(0)$ & & $0(0)$ \\
\hline \multirow[t]{5}{*}{ Larynx } & $290(60.2)$ & $86.9 \%$ & $65(58-71)$ & $1-2$ & $157(54.1)$ & $0(0)$ & 1 & $94(32.4)$ \\
\hline & & & & & & & 2 & $68(23.5)$ \\
\hline & & & & $3-4$ & $133(45.9)$ & $47(35.3)$ & 3 & $53(18.3)$ \\
\hline & & & & & & & 4 & $75(25.9)$ \\
\hline & & & & Missing & $0(0)$ & $0(0)$ & & $0(0)$ \\
\hline \multirow[t]{5}{*}{ OC, OP, HP NOS } & $5(1.0)$ & $80.0 \%$ & $64(51-69)$ & $1-2$ & $3(60.0)$ & 1 (33.3) & 1 & $1(20.0)$ \\
\hline & & & & & & & 2 & $3(60.0)$ \\
\hline & & & & $3-4$ & $2(40.0)$ & $2(100.0)$ & 3 & - \\
\hline & & & & & & & 4 & $1(20.0)$ \\
\hline & & & & Missing & $0(0)$ & $0(0)$ & & $0(0)$ \\
\hline \multirow[t]{5}{*}{ Total } & 482 & $79.1 \%$ & $64(57-70)$ & $1-2$ & $221(45.9)$ & $0(0)$ & 1 & $120(25.1)$ \\
\hline & & & & & & & 2 & $135(28.2)$ \\
\hline & & & & $3-4$ & 261 (54.2) & $130(50.4)$ & 3 & 73 (15.3) \\
\hline & & & & & & & 4 & 150 (31.4) \\
\hline & & & & Missing & $0(0)$ & $4(0.8)$ & & $4(0.8)$ \\
\hline
\end{tabular}


Table II. Treatment of head and neck cancer cases according to tumour stage.

\begin{tabular}{lcc} 
Treatment & \multicolumn{2}{c}{ Stage $\mathbf{n}(\%)$} \\
& $1-2$ & $3-4$ \\
Radiation & $50(22.7)$ & $4(1.5)$ \\
Surgery & $134(60.9)$ & $52(20.1)$ \\
Chemotherapy and Radiation & $16(7.3)$ & $69(26.6)$ \\
Surgery and Radiation & $19(8.6)$ & $73(28.2)$ \\
Surgery and Chemotherapy & $1(0.5)$ & $7(2.7)$ \\
Surgery and Chemotherapy and & - & $54(20.9)$ \\
Radiation & & \\
Missing & 1 & 2 \\
Total & $221(45.9)$ & $261(54.1)$ \\
\hline
\end{tabular}

in laryngeal cancer (16.2\%), unlike oral cavity $(31.3 \%)$, oropharyngeal (48.9\%) and hypopharyngeal $(70.0 \%)$ cancers. Treatment of HNC cases according to tumour stage is reported in Table II: for patients with an early stage tumour exclusive surgery was the treatment of choice $(60.9 \%)$, while in the advanced stages (SIII-SIV) the most widely performed treatments were combined surgery with post-operative radiotherapy (Surg/RT, 28.2\%) and chemotherapy with radiotherapy (CHT/RT, 26.6\%).

\section{Overall survival}

Median follow-up time since cancer diagnosis was 49 months (IQR: 19-86) (Table III). During follow-up, 190 of 482 patients $(39.4 \%)$ died, of which $97(51.1 \%)$ died for HNC cancer, 26 (13.7\%) for other cancer and the remaining 67 for other causes (data not shown). Percentages of death for other causes were as follows: oral cavity $10.1 \%$, oropharynx $11.8 \%$, hypopharynx $8.3 \%$ and larynx $15.0 \%$. Five-years OS for all HNC sites combined was $60.6 \%$ : oral cavity $49.0 \%$, oropharynx $54.8 \%$, hypopharynx $50.0 \%$ and larynx $63.4 \%$. Median survival time in months was higher for laryngeal cancer than for the other tumour sites [(59 vs 23 months, oral cavity $p=0.002), 43$ (oropharynx $p=0.023$ ), 35 (hypopharynx $p=0.03$ )] (Fig. 1). When stratifying the survival time by tumour stages, we did not find significant differences for any cancer sites for early stage tumour sites, while for the advanced tumour stages we observed higher survival for laryngeal cancer than for oral cavity cancer ( $p=0.008$ ) (Figs. 2, 3).

Table IV reports the distribution for selected covariates and the HR for all-cause mortality adjusted for age, stage and lymph node status. Reduced survival was associated with increasing age of diagnosis $(\mathrm{HR}=1.04 ; 95 \% \mathrm{CI}$ : $1.02-1.05)$, and advanced tumour stage $(\mathrm{HR}=2.00 ; 95 \%$ CI: 1.41-2.84).

\section{Cancer recurrence and second primary cancer}

Demographic, clinical and lifestyle characteristics and the association with recurrence and SPC are reported in Table V. Among the $482 \mathrm{HNC}$ patients included, disease recurrence was unknown for $26(5.4 \%)$ patients. and 12 $(2.5 \%)$ patients did not report the date of recurrence. A total of $181(39.7 \%)$ patients developed clinical recurrence. The risk of recurrence was associated with drinking 8-14 drinks per week $(\mathrm{HR}=1.73$; 95\% CI: 1.00-2.97).

Among the $482 \mathrm{HNC}$ patients included, information on SPC were unknown for 17 (3.5\%) patients and 17 (3.5\%) patients did not report the date of second primary, therefore there were 448 patients with complete information on SPC. A total of $169(40.0 \%)$ patients developed SPC. The risk of developing SPC increased with advanced tumour stage $(\mathrm{HR}=2.75 ; 95 \% \mathrm{CI}: 1.39-5.44)$ and with smoking for more than 40 years $(\mathrm{HR}=3.68 ; 95 \% \mathrm{CI}: 1.10-12.30)$.

\section{Discussion}

Many therapeutic options are available for patients with $\mathrm{HNC}$, but the appropriate regimen for the individual patient is still a difficult and often controversial choice. Worldwide, HNC is the sixth most common neoplasm, and despite advances in therapy, long-term survival in

Table III. Median survival time and deaths by tumour site.

\begin{tabular}{|c|c|c|c|c|c|c|}
\hline \multirow[t]{2}{*}{ Follow-up time (months) } & \multicolumn{6}{|c|}{ Deaths } \\
\hline & $\mathrm{N}$ & Median & $1 Q$ & $3 Q$ & $\mathrm{n}$ & $\%$ \\
\hline Oral cavity (OC) & 83 & 23 & 10 & 60 & 34 & $41.0 \%$ \\
\hline Oropharynx (OP) & 84 & 43 & 16 & 82 & 38 & $45.2 \%$ \\
\hline Hypopharynx (HP) & 20 & 35 & 16 & 72 & 10 & $50.0 \%$ \\
\hline Larynx & 290 & 59 & 26 & 94 & 106 & $36.6 \%$ \\
\hline OC, OP, HP NOS & 5 & 71 & 63 & 82 & 2 & $40.0 \%$ \\
\hline Total & 482 & 49 & 19 & 86 & 190 & $39.4 \%$ \\
\hline
\end{tabular}

1Q: first quartile, 3Q: third quartile. NOS, not otherwise specified 


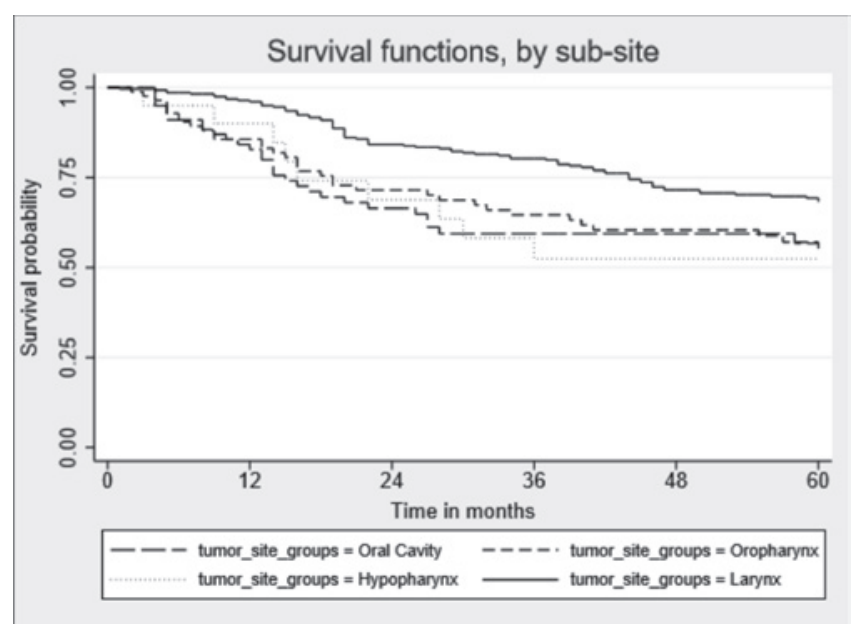

Fig. 1. Kaplan-Meier unadjusted overall 5 -year survival by head and neckcancer site.

HNSCC patients is poor. The prognosis for HNC overall has improved slightly since the 1990 s, and is influenced by site, stage, molecular markers and HPV status. Prognostic factors can guide the physician in selecting the best possible treatment for each patient, possibly increasing the therapeutic index 223 .

In our analysis, many factors showed an association with one or more of the outcomes. Many are well known in the literature.

For instance, age has a negative impact on the prognosis of patients included in our analysis. Other authors observed that older patients have similar survival outcomes compared with their younger peers; however, they may experience worse toxicity, especially with treatment intensification ${ }^{24}$. As life expectancy increases, surgeons can expect an increasing number of geriatric patients. Management of this subpopulation has become a source of debate because there is a paucity of randomised data regarding the effect of age on treatment response and morbidity associated with the treatment of HNC ${ }^{25} 26$.

The heterogeneity of HNC creates various difficulties, first of all for tumour site classification. The site of origin is an important prognostic factor, both because of the different stage at diagnosis and because of the different possibilities of surgical treatment. One must pay attention to laryngeal and oropharyngeal classification for suprahyod larynx or oral and oropahryngeal classification for the base of the tongue.

Tumour staging is a well identified prognostic factor for HNC. A large proportion of patients with HNC are often not diagnosed until their disease has reached an advanced stage, requiring aggressive and costly treatment that may not be curative, with relapse occurring in around $50 \%$ of cases with locally advanced $\mathrm{HNC}^{27} 28$.

We report a significant association between advanced tumour stage (S III-IV) and poor overall and disease-specific survival. The choice of treatment for advanced HNC did not influence time-survival as for other authors ${ }^{29}$. We were unable to find

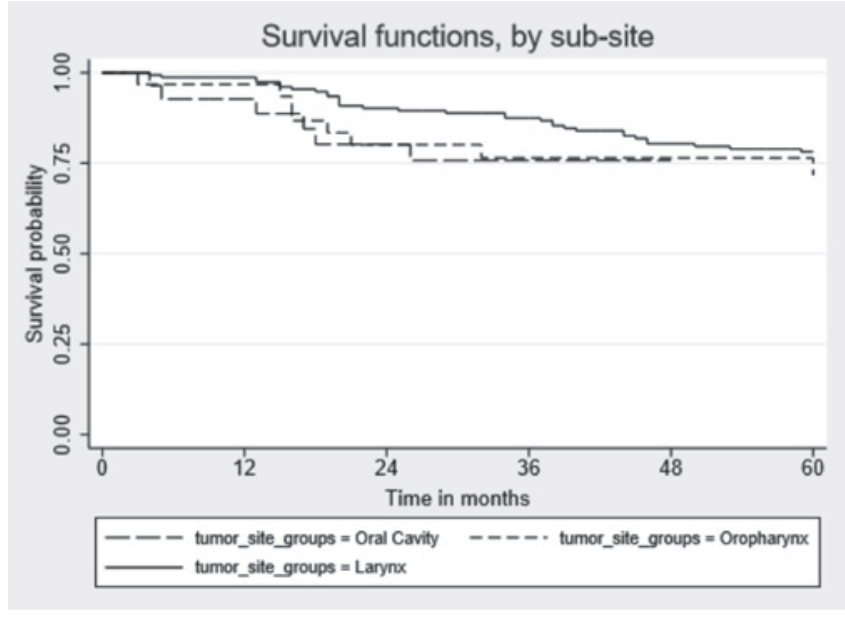

Fig. 2 Kaplan-Meier unadjusted overall 5-year survival by head and neck cancer site for early stage tumours.

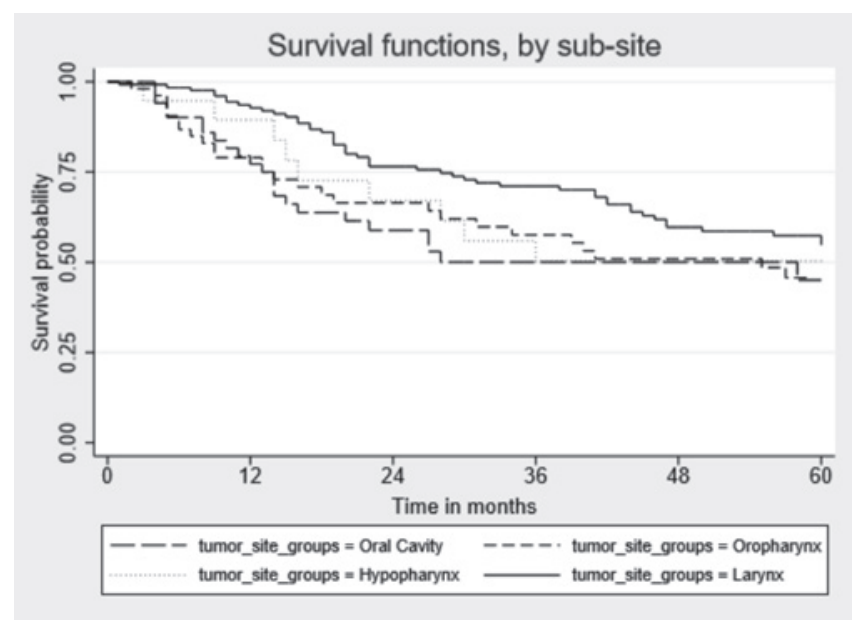

Fig. 3. Kaplan-Meier unadjusted overall 5 -year survival by head and neck cancer site for advanced stage tumours.

any significant factor that may constitute a contraindication for a combined approach with RT and CHT or surgery/CHTRT, and identify advanced HNC patients for whom a palliative approach or best supportive care could be preferred.

Smoking and high alcohol consumption habits are not only well-known causative but also prognostic factors in $\mathrm{HNC}^{30}$. In our experience, a long history of smoking impacted SPC development. HNC patients have a higher risk of second primary tumours than the general population. The most frequent locations are the head and neck, lung and oesophagus, decreasing long-term survival. The incidence of SPC has increased in the last decade, with a negative effect on survival. Since no specific early diagnostic tool is available, alcohol and tobacco avoidance along with scheduled follow-up are suggested to reduce its incidence ${ }^{31-33}$.

In recent years, HPV status was found to play a major role as a prognostic and predictive parameter, especially 
Table IV. Predictors of overall survival among head and neck cancer cases by multivariate analysis.

\begin{tabular}{|c|c|c|c|}
\hline & \multicolumn{2}{|c|}{ Subjects } & \multirow{2}{*}{$\begin{array}{c}\text { Death from all causes } \\
\text { (total/deaths 482/190) } \\
H^{*}(95 \% \mathrm{Cl})\end{array}$} \\
\hline & $n$ & $\%$ & \\
\hline \multicolumn{4}{|l|}{ Demographics } \\
\hline Age at diagnosis (ordinal) & 482 & 100 & $1.04(1.02-1.05)$ \\
\hline \multicolumn{4}{|l|}{ Gender } \\
\hline Men & 381 & 81.2 & 1.00 \\
\hline Women & 88 & 18.8 & $0.92(0.63-1.35)$ \\
\hline \multicolumn{4}{|l|}{ Tumour characteristics } \\
\hline \multicolumn{4}{|l|}{ Stage } \\
\hline |/II & 221 & 45.9 & 1.00 \\
\hline III/IV & 261 & 54.1 & $2.00(1.41-2.84)$ \\
\hline \multicolumn{4}{|c|}{ Cigarette smoking and alcohol consumption } \\
\hline \multicolumn{4}{|c|}{ Smoking status } \\
\hline Never & 68 & 14.6 & 1.00 \\
\hline Former & 259 & 55.6 & $1.15(0.73-1.81)$ \\
\hline Current & 139 & 29.8 & $1.20(0.73-1.98)$ \\
\hline \multicolumn{4}{|l|}{ Years of smoking } \\
\hline Never smokers & 68 & 14.1 & 1.00 \\
\hline$\leq 20$ & 56 & 11.6 & $0.93(0.49-1.75)$ \\
\hline $21-40$ & 199 & 41.3 & $1.16(0.72-1.86)$ \\
\hline$>40$ & 159 & 33.0 & $1.22(0.76-1.97)$ \\
\hline \multicolumn{4}{|l|}{ Cigarettes per day } \\
\hline Never smokers & 68 & 14.1 & 1.00 \\
\hline$\leq 20$ & 234 & 48.5 & $1.16(0.74-1.84)$ \\
\hline$>20$ & 180 & 37.3 & $1.14(0.71-1.85)$ \\
\hline \multicolumn{4}{|l|}{ Drinking status } \\
\hline Never & 100 & 21.4 & 1.00 \\
\hline Former & 19 & 4.1 & $0.83(0.29-2.35)$ \\
\hline Current & 348 & 74.5 & $1.27(0.86-1.87)$ \\
\hline \multicolumn{4}{|l|}{ Drinks per week } \\
\hline Never drinkers or $<1$ & 81 & 16.8 & 1.00 \\
\hline $1-7$ & 48 & 10.0 & $1.33(0.74-2.39)$ \\
\hline $8-14$ & 113 & 23.4 & $1.36(0.86-2.16)$ \\
\hline $15-21$ & 32 & 6.6 & $0.98(0.49-1.98)$ \\
\hline $22-28$ & 58 & 12.0 & $1.15(0.66-1.99)$ \\
\hline$>28$ & 150 & 31.1 & $1.52(0.94-2.45)$ \\
\hline
\end{tabular}

Text in bold indicates statistically significant risk factors. HR: hazard ratio; Cl: confidence interval. * HR adjusted by age, stage, Iymph nodes.

in oro-pharyngeal cancer. HPV-positivity is a consistent determinant of superior survival irrespective of the treatment approach used ${ }^{34-36}$. Unfortunately, evaluation of HPV status in HNC entered our clinical practice only a few years ago. For this reason, these data are not available for most patients in our series, making it impossible to obtain a significant analysis.

Apart from HPV, many other biological parameters have been studied as prognostic factors in $\mathrm{HNC}$ patients. For istance, a recent meta-analysis on $\mathrm{HNC}$ patients confirmed the negative impact of epidermal-growth factor (EGFR) overexpression ${ }^{37}$. In the near future, analysis of these parameters could help physicians in selection of the best treatment approach for each individual patient ${ }^{38}$. Unfortunately, as for HPV, our analysis did not investigate such parameters, because data were missing in a signifi- 
Table V. Predictors of recurrence and second primary among head and neck cancer cases by multivariate analysis.

\begin{tabular}{|c|c|c|}
\hline & $\begin{array}{c}\text { Recurrence } \\
n=169\end{array}$ & $\begin{array}{l}\text { Second primary } \\
\quad n=60\end{array}$ \\
\hline & $\mathrm{HR}(95 \% \mathrm{Cl})^{\mathrm{a}}$ & $\mathrm{HR}(95 \% \mathrm{Cl})^{\mathrm{b}}$ \\
\hline \multicolumn{3}{|l|}{ Demographics } \\
\hline Age at diagnosis (ordinal) & $1.00(0.98-1.02)$ & $1.02(0.99-1.05)$ \\
\hline \multicolumn{3}{|l|}{ Gender } \\
\hline Men & 1.00 & 1.00 \\
\hline Women & $0.69(0.42-1.13)$ & $1.57(0.76-3.23)$ \\
\hline \multicolumn{3}{|l|}{ Tumour characteristics } \\
\hline \multicolumn{3}{|l|}{ Stage } \\
\hline 1/ll & 1.00 & 1.00 \\
\hline III/IV & $0.99(0.61-1.60)$ & $2.75(1.39-5.44)$ \\
\hline \multicolumn{3}{|c|}{ Cigarette smoking and alcohol consumption } \\
\hline \multicolumn{3}{|c|}{ Smoking status } \\
\hline Never & 1.00 & 1.00 \\
\hline Former & $0.93(0.54-1.58)$ & $2.64(0.80-8.69)$ \\
\hline Current & $0.61(0.33-1.14)$ & $3.28(0.94-11.47)$ \\
\hline \multicolumn{3}{|l|}{ Years of smoking } \\
\hline Never smokers & 1.00 & 1.00 \\
\hline$\leq 20$ & $0.77(0.38-1.58)$ & $1.91(0.42-8.75)$ \\
\hline $21-40$ & $0.90(0.51-1.57)$ & $2.34(0.69-7.93)$ \\
\hline$>40$ & $0.71(0.39-1.30)$ & $3.68(1.10-12.30)$ \\
\hline \multicolumn{3}{|l|}{ Cigarettes per day } \\
\hline Never smokers & 1.00 & 1.00 \\
\hline$\leq 20$ & $0.81(0.47-1.39)$ & $2.72(0.82-8.99)$ \\
\hline$>20$ & $0.81(0.45-1.44)$ & $2.97(0.87-10.12)$ \\
\hline \multicolumn{3}{|l|}{ Drinking status } \\
\hline Never & 1.00 & 1.00 \\
\hline Former & $1.21(0.42-3.48)$ & $0.61(0.08-4.78)$ \\
\hline Current & $1.11(0.71-1.74)$ & $0.73(0.35-1.51)$ \\
\hline \multicolumn{3}{|l|}{ Drinks per week } \\
\hline Never drinkers or $<1$ & 1.00 & 1.00 \\
\hline $1-7$ & $1.33(0.66-2.67)$ & $0.85(0.27-2.67)$ \\
\hline $8-14$ & $1.73(1.00-2.97)$ & $0.99(0.41-2.39)$ \\
\hline $15-21$ & $1.07(0.46-2.51)$ & $0.44(0.09-2.12)$ \\
\hline $22-28$ & $0.84(0.41-1.73)$ & $0.78(0.27-2.24)$ \\
\hline$>28$ & $0.91(0.51-1.63)$ & $0.83(0.33-2.11)$ \\
\hline
\end{tabular}

Text in bold indicates statistically significant risk factors. HR: Hazard Ratio; Cl: Confidence Interval. a HR adjusted by age, treatment, lymph nodes. b HR adjusted by age, stage, years of smoking, lymph nodes.

cant proportion of patients included in this series. Another limitation of the study is represented by not having performed the analysis by HNC subsite and not having available data on comorbidities: due to this latter limitation we could not justify the reason for the elevated number of deaths due to causes other than tumour, although is likely that the advanced age of these patients could be the main reason.
Despite these limitations, we feel that our study contributes in identifying prognostic factors for HNC patients, because the data we considered in this series are easy to collect in any department. The number of patients included in this analysis is small, considering the long-time period studied. However, we preferred a more limited number of patients, but with all the required information available and with sufficient follow-up time. 


\section{Conclusions}

$\mathrm{HNC}$ is the sixth most common neoplasm, and despite advances in therapy, long-term survival in HNC patients is poor. Age and tumour staging are considered the most important prognostic factors for overall survival. Recurrence and second primary tumours are influenced negatively by high alcohol consumption and cigarette smoking. Clinical characteristics remain the best known prognostic factors in HNC. A major effort in HNC prevention and modification of patients' behaviour could lead to early diagnosis and reduction of recurrence and second primary tumours.

\section{Funding}

This work was supported by the Associazione Italiana per la Ricerca sul Cancro - AIRC IG 2011 (contract no. 10491) and IG2013 (contract no. 14220), and Fondazione Veronesi. The funders had no role in study design or data analysis.

\section{Acknoledgements}

We acknowledge financial support by the Associazione Italiana per la Ricerca sul Cancro and Fondazione Veronesi.

\section{References}

1 Ferlay J, Soerjomataram I, Ervik M, et al. International Agency for Research on Cancer. World Health Organisation. Globocan: 2012 Estimated cancer incidence, mortality and prevalence worldwide in 2012. Cancer Incidence and Mortality Worldwide: IARC CancerBase No. 11 [Internet]. Lyon, France: International Agency for Research on Cancer; 2013. Available from: http://globocan.iarc.fr.

2 AIRTUM. ITACAN: Tumori in Italia, Versione 2.0. Associazione Italiana dei Registri Tumori (http://www.registritumori.it).

3 Cadoni G, Boccia S, Petrelli L, et al. A review of genetic epidemiology of head and neck cancer related to polymorphisms in metabolic genes, cell cycle control and alcohol metabolism. Acta Otorhinolaryngol Ital 2012;32:1-11.

4 Black RJ, Bray F, Ferlay J, et al. Cancer incidence and mortality in the European Union: Cancer registry data and estimates of national incidence for 1990. Eur J Cancer 1997;33:1075-107.

5 Ferlay J, Shin HR, Bray F, et al. GLOBOCAN 2008 v1.2, Cancer Incidence and Mortality Worldwide. IARC CancerBase No. 10 [Internet] Lyon, France: International Agency for Research on Cancer; 2010. Available from: http://globocan.iarc.fr, accessed on 30/05/2013.

6 Tuyns AJ, Estève J, Raymond L, et al. Cancer of the larynx/hypopharynx, tobacco and alcohol: IARC international case-control study in Turin and Varese (Italy), Zaragoza and Navarra (Spain), Geneva (Switzerland) and Calvados (France). Int J Cancer 1988;41:483-491.

7 Toporcov TN, Znaor A, Zhang ZF, et al. Risk factors for head and neck cancer in young adults: a pooled analysis in the INHANCE consortium. Int J Epidemiol 2015;44:169-85.

8 Galeone C, Edefonti V, Parpinel M, et al. Folate intake and the risk of oral cavity and pharyngeal cancer: a pooled analysis within the International Head and Neck Cancer Epidemiology Consortium. Int J Cancer 2015;136:904-14.

9 Leoncini E, Edefonti V, Hashibe M, et al. Carotenoid intake and head and neck cancer: a pooled analysis in the International Head and Neck Cancer Epidemiology Consortium. Eur J Epidemiol 2016;31:369-83.

10 Leoncini E, Ricciardi W, Cadoni G, et al. Adult height and head and neck cancer: a pooled analysis within the INHANCE Consortium. Eur J Epidemiol 2014;29:35-48.

11 Wyss A, Hashibe M, Chuang SC, et al. Cigarette, cigar, and pipe smoking and the risk of head and neck cancers: pooled analysis in the International Head and Neck Cancer Epidemiology Consortium. Am J Epidemiol 2013;178:679-90.

12 Leoncini E, Vukovic V, Cadoni G, et al. Clinical features and prognostic factors in patients with head and neck cancer: Results from a multicentric study. Cancer Epidemiol 2015;39:367-74.

13 Mork J, Lie AK, Glattre E, et al. Human papillomavirus infection as a risk factor for squamous-cell carcinoma of the head and neck. N Engl J Med 2001;344: 1125-31.

14 Chang ET, Adami HO. The enigmatic epidemiology of nasopharyngeal carcinoma. Cancer Epidemiol Biomarkers Prev 2006;15:1765-77.

15 Berneir J, Domenge C, Ozsahin M et al. European organization for research and treatment of cancer trial 22931 postoperative irradiation with or without concomitant chemotherapy for locally advanced head and neck cancer. N Engl J Med 2004;350:1945-52.

16 Franceschini D, Paiar F, Saieva C et al. Prognostic factors in patients with locally advanced head and neck cancer treated with concurrent radiochemotherapy. Radiol Med 2016;121:229-37.

17 Leoncini E, Vukovic V, Cadoni G, et al. Clinical features and prognostic factors in patients with head and neck cancer: Results from a multicentric study. Cancer Epidemiol 2015;39:37-74.

$18 \mathrm{http} / / /$ www.cdc.gov/nchs/icd/icd9cm.htm

19 Warren S, Gates O. Multiple primary malignant tumours: a survey of literature and statistical study. Am J Cancer 1932;16:1358-414.

20 Schoenfeld D. Partial residuals for the proportional hazards regression model. Biometrika 1982;69:239-41.

21 IARC. Alcoholic beverage consumption and ethyl carbamate (urethane). IARC Monogr Eval Carcinog Risks Hum 2007;96:72-84.

22 Bussu F, Miccichè F, Rigante M, et al. Oncologic outcomes in advanced laryngeal squamous cell carcinomas treated with different modalities in a single institution: a retrospective analysis of 65 cases. Head Neck 2012;34:573-9.

${ }^{23}$ Castaldi P, Rufini V, Bussu F, et al. Can "early" and "late" $18 F-F D G$ PET-CT be used as prognostic factors for the clinical outcome of patients with locally advanced head and neck cancer treated with radio-chemotherapy? Radiother Oncol 2012;103:63-8.

24 VanderWalde NA, Mary Fleming M, Jared Weiss, et al. Treatment of older patients with head and neck cancer: a review. Oncologist 2013;18:568-578. 
25 Genden EM, Rinaldo A, Shaha AR, et al. Treatment considerations for head and neck cancer in the elderly. J Laryngol Otol 2005;119:169-74.

26 Syrigos KN, Karachalios D, Karapanagiotou EM, et al. Head and neck cancer in the elderly: an overview on the treatment modalities. Cancer Treat Rev 2009;35:237-45.

27 Argiris A, Eng C. Epidemiology, staging, and screening of head and neck cancer. Cancer Treat Res 2003;114:15-60.

28 Bussu F, Miccichè F, Rigante M, et al. Oncologic outcomes in advanced laryngeal squamous cell carcinomas treated with different modalities in a single institution: a retrospective analysis of 65 cases. Head Neck 2012;34:573-9.

29 Adelstein DJ, Lavertu P, Saxton JP, et al. Mature results of a phase III randomized trial comparing concurrent chemoradiotherapy with radiation therapy alone in patients with stage III and IV squamous cell carcinoma of the head and neck. Cancer 2000;88:876-83.

30 Leoncini E, Vukovic V, Cadoni G, et al. Clinical features and prognostic factors in patients with head and neck cancer: Results from a multicentric study. Cancer Epidemiol 2015;39:367-74.

31 Lee DH, Roh JL, Baek S, et al. Second cancer incidence, risk factor, and specific mortality in head and neck squamous cell carcinoma. Otolaryngol Head Neck Surg 2013;149:579-86.

32 Schwartz LH1, Ozsahin M, Zhang GN, et al. Synchronous and metachronous head and neck carcinomas. Cancer 1994;74:1933-8.

33 Herranz González-Botas J, Varela Vázquez P, Vázquez Barro C. Second primary tumours in head and neck cancer. Acta Otorrinolaringol Esp 2016;67:123-9.

34 Boscolo-Rizzo P, Del Mistro A, Bussu F, et al. New insights into human papillomavirus-associated head and neck squamous cell carcinoma. Acta Otorhinolaryngol Ital 2013;33:77-87.

35 Sedghizadeh PP, Billington WD, Paxton D, et al. Is p16-positive oropharyngeal squamous cell carcinoma associated with favorable prognosis? A systematic review and meta-analysis. Oral Oncol 2016;54:15-27.

${ }^{36}$ Lassen P, Eriksen JG, Krogdahl A, et al. The influence of $H P V$-associated p16-expression on accelerated fractionated radiotherapy in head and neck cancer: evauatio of the randomized DAHANCA 6\&7 trial. Radiother Oncol 2011;100:49-55.

37 Keren S, Shoude Z, Lu Z, et al. Role of EGFR as a prognostic factor for survival in head and neck cancer: a meta-analysis. Tumour Biol 2014;35:2285-95.

38 Gollin SM. Cytogenetic alterations and their molecular genetic correlates in head and neck squamous cell carcinoma: a next generation window to the biology of disease. Genes Chromosomes Cancer 2014;53:972-90.

Received: May 25, 2016 - Accepted: January 15, 2017

Address for correspondence: Gabriella Cadoni, Institute of Otorhinolaryngology, Università Cattolica del Sacro Cuore, Fondazione Policlinico Universitario “Agostino Gemelli”, Rome, Italy. Tel. +39 06 30154439. E-mail: gabriella.cadoni@rm.unicatt.it 